Kretsai Woottipong'

Thaksin University, Faculty of Humanities and Social Sciences Thailand
Original scientific paper

UDC: 37.015 .3

DOI: $10.5937 /$ istrped2001032W

\title{
INVESTIGATION INTO THAI HIGH SCHOOL LEARNERS' SELF-REGULATED LEARNING SKILLS, SELF-EFFICACY AND WRITING PERFORMANCE
}

\begin{abstract}
This study aimed to investigate Thai high school students' reported use of SRL strategies and their self-efficacy and to explore the effects of two psychological determinants in writing performance. Data were gathered from 768 Thai high school students in six high schools located in Southern Thailand. Convenience sampling was used in this study. The research instruments included self-report surveys to examine their reported use of SRL strategies and perceived self-efficacy and a given-topic essay writing test to evaluate their writing performance. The results revealed that grade level and writing proficiency were important factors influencing students' reported use of SRL strategies. Multiple regression analyses showed that SRL strategies and self-efficacy had a positive effect on students' writing performance.
\end{abstract}

Key words: self-regulated learning skills, self-efficacy, writing performance.

\section{Introduction}

Writing is viewed as one of the most problematic areas for learners learning to write in a foreign language. The characteristics of effective written work include cohesion and good structure, logical development of ideas and correct use of vocabulary and mechanics (Hall, 1988). Many studies have been done in order to find practical and effective methods to motivate students to write, but learners seem to possess negative attitudes towards writing with the application of many pedagogical methods. For example, learners are worried about inappropriate use of structure, and they have low self-efficacy while writing. Thus, it is crucial to identify the challenges learners encounter in their writing in order to employ pedagogical practices that increase their awareness and use of learning strategy and to help them develop their writing ability and enhance their motivation.

As regards the challenges faced by learners described above, it is crucial to conduct studies on teaching writing in a more systematic way and utilize various methods and techniques in teaching writing. One of these methods is writing training based on self-regulation. According to Graham, Harris and Mason (2005), the learning strategy based on self-regulation encourages learners to increase planning and self-regulation skills, which are important to control their writing practice, gain more understanding in the writing process, and apply the strategy they learned.

\footnotetext{
1'kretsai@yahoo.com
} 
Self-regulation has been accepted as one of the key mechanisms that may increase learner achievement, motivation, and use of learning strategies, which are the main causes of completion rate in high school education. Self-regulation is important for the processes of learning (Jarvela \& Jarvenoja, 2011). It can motivate learners to develop better learning behaviour and promote their study skills (Wolters, 2011), generalize learning strategies to achieve academic learning outcomes and control their learning performance (Harris et al., 2005), and reflect their own learning development (de Bruin, Thiede \& Camp, 2011). Studies have emphasized empirical exploration on cognitive and metacognitive strategies in L1 reading and writing (Harris, Graham, MacArthur, Reid, \& Mason, 2011). A study conducted by Lee (1997) revealed that regulation had a positive impact on learning success, but traditional school instruction generally assumes that students have regulation skills and does not provide opportunities for them to develop these skills.

In writing, the learners become self-regulated when they are able to adjust their own writing strategies by changing writing situations such as audience (Magno, 2009). Magno further states that each writing stage involves the individual's motivation in tasks and processes, including specific self-regulation elements such as memory strategy, goal-setting, selfevaluation, help-seeking, environmental structuring, and organizing. Zimmerman and Martinez-Pons (1992) described the elements of self-regulation useful for writing tasks. This model explains that learning approaches as processes can be deployed to nurture learners to become self-regulated in writing. Writing requires planning, translating, executing, evaluating, and revising. The steps on planning, translating, and executing represent learning approaches as they involve developing ideas, translating ideas into texts, and writing the content. Writing well in another language would involve more and higher cognitive skills (Lenski, 1998 as cited in Magno, 2009).

The writing process would involve a test of a person's memory, language repertoire and thinking ability instantaneously. Before a writing task is regulated through strategies, the writer needs to have a deep understanding of the conceptualization of the topic (Kellogg, 2001). However, only limited explicit research of writing strategies based on SRL theories particularly in English as a Foreign Language (EFL) teaching environments has been conducted.

While there have been several studies showing a positive relationship between self-regulated learning strategies and academic success, to the best of my knowledge, little attention has been devoted to identifying the relations among the use of self-regulated learning strategies, self-efficacy perceptions and writing performance especially in a Thai high school context. The present investigation sought to demonstrate the current situation of the self-regulation and self-efficacy levels students have while learning, and their effects on writing performance in Thai high school learning settings. The findings of this preliminary study were used as data to design the intervention for Thai high school learners in which the details were not included in this article.

\section{Literature review}

\section{Self-regulated learning and self-efficacy}

Self-regulated learning refers to the way the one uses his/her own resources to plan, control and analyze the execution of activities, and tasks, and the preparation of learning products (Schunk \& Zimmerman, 1994). According to Schunk and Zimmerman (1997), the features of 
self-regulated learners include: 1) using different learning strategies, 2) being self-efficient when generalizing the strategies, and 3) being committed to achieving learning goals. The key objective of self-regulation learning is to ensure that the entity involved in it is capable of developing and seeking its inherent quality and that such culture is stemmed from the willingness of the learners who are part of it.

In academic settings, self-efficacy influences the utilization of self-regulation. BouffardBouchard, Parent and Larivee (1991) explored the impact of self-efficacy on self-regulation during a verbal concept formation task of learners with average or above average cognitive ability when they attempted to solve four problems of different levels of difficulty after the evaluation of self-efficacy. The findings revealed that self-efficacy had positive impact on many aspects of self-regulation, specifically in controlled time-on-task, task persistence, and performance in various levels of school grade and cognitive abilities. High self-efficacy students demonstrated a better monitoring of their working time and were more persistent on the task than students with low self-efficacy. When learners have the necessary cognitive skills to solve the problems, the same levels of self-efficacy tend to lead to the same influences on self-regulation and performance, regardless of the school grade (BouffardBouchard, Parent \& Larivee, 1991).

\section{Self-regulated learning (SRL) Strategies and Writing}

Writing based on self-regulation refers to the thoughts, emotions, and acts which learners employ to achieve various writing tasks by regulating the writing process (Schunk \& Zimmerman, 2007). Learners should regulate their writing process, convey their emotions, and generate ideas using correct sentences based on a specific plan during the process of writing. This can be done through the generalization of the writing strategy based on selfregulation. Self-regulated learners are those who are aware of their writing and reading strategies, understand when to apply the strategy, and perform the things they need to do throughout the writing process in a planned and systematic way. Self-regulation is a skill that can be taught to the students. This means that the learning and teaching activities provided in educational settings should be managed in accordance with self-regulation (Zimmerman, 2002).

Based on the literature reviewed above, self-regulation is crucial for learners to achieve in learning to write, and this motivated the researcher to conduct this study in the secondary schools located in the south of Thailand. The results of this study will be beneficial for instructors who design curriculum and those who plan to gain an understanding of the factors necessary in nurturing self-regulation learning habits in writing to help learners become efficient writers. Thus, the aims of this study are to explore:

1) the relationship between Thai EFL high school students' deployment of SRL strategies and their grade levels,

2) the correlations between the students' perceived self-regulated learning strategies and their perceived self-efficacy in Thai EFL writing, and

3) the relationship between the learners' perceived self-regulated learning strategies and their perceived self-efficacy based on their writing test scores. 


\section{Method}

\subsection{Participants}

A total of 768 upper-secondary school students from six upper-secondary schools in the south of Thailand participated in this study in three rounds on a voluntary basis. Convenience sampling was used, and participants from the non-science upper secondary schools were generally similar in terms of their education background and age.

During the pilot study, a total number of 318 upper-secondary school students from four medium-ranking upper-secondary schools in the south of Thailand participated in this study to test the two modified surveys (SLWS and WSS). This was a convenience sample, with participants selected from grades 10 to 12 (37.73\% grade $10,29.26 \%$ grade 11 and $33.01 \%$ grade 12). Of these, 65.09 percent $(n=207)$ were females and 34.91 percent $(n=111)$ were males between the ages of 15 and $19(M=16.99, S D=1.037)$.

In the main study, another group of 364 upper-secondary school students from three other upper-secondary schools in the same regional area participated in this phase. All the participants were students across the upper-secondary schools, ranging from grades 10 to 12 (36\% grade $10,31.04 \%$ grade 11 , and $32.96 \%$ grade 12 ). There were more females $(n=186$, $51.09 \%)$ than males $(n=178,48.91 \%)$ between the ages of 15 to $20(M=17.19, S D=1.148)$. Based on the students' writing test scores, the sample was further divided into two groups: highskilled writers $(n=108)$, students with writing test scores of 70 or higher; and low-skilled writers $(n=112)$, students with writing test scores of 50 or below.

\subsection{Instruments}

\subsubsection{Developing Constructivist Self-regulated Learning in Writing Survey (CSLWS)}

All the students participated in this phase completed the Developing Constructivist Selfregulated Learning in Writing Survey (CSLWS) in Thai. The survey was composed of demographic information and the two finalized surveys to examine the students' selfregulatory strategies and their self-efficacy in EFL writing contexts. The first section aimed to collect the participants' demographic data in terms of their years of English learning, age and grade level. The second section was the Self-regulated Learning in Writing Survey (SLWS) with 41 items examining students' deployment of self-regulatory strategies in terms of cognition, metacognition, motivational and environmental aspects. The third section had 18 items of the Writing Self-efficacy Survey (WSS) including the three aspects of language, self-regulation and writing performance. These tools were validated with satisfactory psychometric properties in the preliminary phase.

\subsubsection{Writing test}

The students' writing performance was measured using an argumentative paragraph based on a given topic. The selected topic for this study was general, culturally inoffensive and familiar to participants' daily life to ensure fairness to all the participants. Essay writing with a given topic related to the students' learning or life was used with written prompts to investigate a relatively more comprehensive picture of writing proficiency. All the participants were required to write an argumentative paragraph with at least 170 words within 60 minutes 
during the Reading and Writing class. The time limit of one hour and the minimum requirement of 170 words were devised to balance the demands on the participants' time with a reasonable level of task difficulty and complexity. The in-class test with the limited time was employed to control many other factors affecting students' writing performance such as copying contents from others or searching information from the internet.

\subsubsection{Validity and reliability of instruments}

\subsubsection{Preparatory Stage - Instrument Validation}

\subsubsection{The reliability and validity of the writing assessment}

In order to ensure the reliability and validity of the writing assessment, the overall quality of these essays was marked based on Jacobs et al. (1981) ESL Composition Profile. The weighting assigned to each rating scale of each aspect of writing was adapted as per the suggestion of language specialists in terms of content, organization, vocabulary, grammar (language use) and punctuations. The full score of each part was adapted from Jacobs at el. (1981) as detailed below:

Table 1. Full Score of Each Aspect of Writing

\begin{tabular}{lllllll}
\hline Student No. & Content & Organization & $\begin{array}{l}\text { Language } \\
\text { use }\end{array}$ & Vocabulary & Mechanics & Total score \\
\hline 30 marks & 30 marks & 20 marks & 10 marks & 10 marks & 100 marks \\
\hline
\end{tabular}

A total of 318 essays were collected in the pilot phase. Then all these papers were typed before marking, and the participants' identifying information was deleted. All the data were coded blindly and all paragraphs were recorded in word-processor files to standardize the paragraph format and avoid handwriting bias by evaluators. Before the practical marking was done, two independent raters, who are experienced EFL teachers attended a rater training session. Neither of them was familiar with the research design to avoid bias when they evaluated these paragraphs. A short rater training document contained the scoring rubric, instructions for how the rating process would be done, and marked scripts explaining different levels of performance.

During the piloting phase, the two raters were first invited to independently re-score 72 randomly selected scripts (around $20 \%$ of the original samples) to set the intrarater reliability (agreement). The intra-rater coefficient for the first rater was $r=.87, p<.001$ and for the second rater was $r=.89, p<.001$ and their inter-rater reliability between the raters was $r=.84$, $\mathrm{p}<.001$, showing satisfactory reliability. Then they were given the remaining writing samples to evaluate separately.

\subsubsection{The Construction of Self-regulated Learning in Writing Survey (SLWS)}

The three sub-scales in the learning strategies section of the "Motivated Strategies for Learning Questionnaire (MSLQ)" constructed by Pintrich et al (1991) was selected as a guideline for the generation of the survey. The MSLQ originally included 81 items and was a self-report instrument designed to assess motivational orientations and use of learning strategies by college students. The SLWS is a modified version of "Part B. Learning Strategies" of the MSLQ. A list of 47 items related to EFL writing strategies was constructed. The value of 
IOC was between 0.6-1.0. The lowest rating of six items was deleted. The revised survey was administered to six EFL students for clarity and readability. The finalized survey consisted of 41 items with a 5-point Likert scale ranging from 1 to 5 . The internal-consistency coefficient alpha of the SLWS was .90, and the Guttman Split-Half coefficient was .84 based on the pilot study. The details of the four dimensions in the survey are described below:

There were 12 items used to measure the learners' use of metacognitive strategies. In this survey, the metacognitive strategies included planning, organizing, monitoring, and regulating. The internal-consistency coefficient alpha of reliability for metacognitive strategies of this survey was .78 . For this study, the Cronbach's alpha for metacognitive strategies was .70. There were 10 items used to measure the learners' use of cognitive strategies. In this questionnaire, the cognitive strategies included rehearsal, mnemonics, and text analysis strategies. The average internal-consistency coefficient alpha of reliability for cognitive strategies of this survey was .71. For this study, the Cronbach's alpha for cognitive strategies was .84. There were 10 items used to measure the learners' use of resource-management strategies. In this questionnaire, the environmental strategies included help seeking and peer learning strategies. The average internal-consistency coefficient alpha of reliability for environmental strategies of this survey was .75. For this study, the Cronbach's alpha for resource management strategies was .79. There were nine items used to measure the learners' use of motivational strategies. In this survey, the motivational strategies included motivation self-talk and interest enhancement. The average internal-consistency coefficient alpha of reliability for motivational strategies of this survey was .73. For this study, the Cronbach's alpha for resource management strategies was .80.

\subsubsection{The construction of Writing Self-efficacy Survey (WSS)}

The Writing Self-efficacy Survey (WSS) was adapted from the Guide for Constructing SelfEfficacy Scales (Bandura, 2006), the Writing Self-Efficacy Scale (WSES) (Pajares, 2007) and Second Language Writer Self-Efficacy Scale (L2WSS) (Teng, 2016). A list of 25 items was constructed. The selection of questions focuses on the three aspects of knowledge, behaviour, and regulation adapted to learning in $L 2$ writing. The instrument was designed with a 5-point Likert scale. The value of $10 C$ was between 0.6-1.0. The revised survey was administered to six EFL students for clarity and readability. The finalized survey consisted of 18 items with a 5-point Likert scale ranging from 1 to 5 and was employed to explore the participants' confidence in using three distinct aspects of linguistic knowledge, performance, and self-regulation. The internal-consistency coefficient alpha of the WSS was .92, and the Guttman Split-Half coefficient was .81 based on a pilot study in August 2017. The details of each aspect in the survey are described below:

There were six items used to measure the learners' use of language self-efficacy strategies. The average internal-consistency coefficient alpha of reliability for motivational strategies of this survey was .75. For this study, the Cronbach's alpha for resource management strategies was .79. There were five items used to measure the learners' use of self-regulatory efficacy strategies. The average internal-consistency coefficient alpha of reliability for motivational strategies of this survey was .80. For this study, the Cronbach's alpha for resource management strategies was .86. There were seven items used to measure the learners' use of writing performance self-efficacy strategies. The average internal-consistency coefficient alpha of reliability for motivational strategies of this survey was .81. For this study, the Cronbach's alpha for resource management strategies was .87. 


\subsection{Procedures}

1. All the participants completed the Developing Constructivist Self-regulated Learning in Writing Survey (CSLWS) that was constructed to collect the participants' demographic information and two surveys to elicit information about their deployment of self-regulatory strategies and self-efficacy.

2. They were asked to return the surveys within three days. This was an anonymous survey, and instructions were explained first.

3. On the following day, these students were asked to take an in-class writing test during one regularly scheduled class within 60 minutes.

4. All the participants were informed on the objectives of the study and their rights to withdraw from the research at any time during or after the data collection period. It was explained that there were no right or wrong answers, and participation or absence would not affect their normal courses, grade, or relationship with their teachers and that there was no assessment on their performance and grade.

\subsection{Data analysis}

In this study, MANOVA was used to examine whether there was a relationship between the students' deployment of four aspects of self-regulatory strategies and their grade levels. Pearson correlation was conducted to examine the relationships between the use of selfregulatory strategies and self-efficacy in writing. Multiple regression analysis was conducted to examine the effect of self-regulatory strategies and self-efficacy on students' writing test scores.

\section{Result and discussion}

\subsection{Findings in relation to the first research objective}

Table 2 presents the descriptive statistics of the eight self-regulatory strategies, ranging from 2.426 ( SD = 1.097) for help-seeking to 3.033 ( $S D=1.070)$ for interest enhancement. Paired samples $t$-tests were used to compare the differences between the four dimensions of selfregulatory strategies and the eight sub-strategies.

Table 2. Descriptive Statistics and Results of Paired Samples t-tests of SRL Strategies $(N=364)$

\begin{tabular}{|c|c|c|c|c|c|c|c|c|c|c|c|c|c|}
\hline \multirow{2}{*}{$\begin{array}{l}\text { Self- } \\
\text { regulatory } \\
\text { strategies }\end{array}$} & \multirow[t]{2}{*}{$M$} & \multirow[t]{2}{*}{ SD } & \multirow[t]{2}{*}{$\mathrm{t}$} & \multirow[t]{2}{*}{$p$} & \multicolumn{2}{|c|}{$95 \% \mathrm{Cl}$} & \multirow{2}{*}{$\begin{array}{l}\text { Eight sub- } \\
\text { strategies }\end{array}$} & \multirow[t]{2}{*}{$M$} & \multirow[t]{2}{*}{$\mathrm{SD}$} & \multirow[t]{2}{*}{$t$} & \multirow[t]{2}{*}{$\mathrm{p}$} & \multicolumn{2}{|c|}{$95 \% \mathrm{Cl}$} \\
\hline & & & & & LL & UL & & & & & & $\mathrm{LL}$ & UL \\
\hline \multirow{5}{*}{$\begin{array}{l}\text { Cognitive } \\
\text { strategies }\end{array}$} & 2.7 & .78 & 67.4 & $<$ & 2.6 & 2.8 & \multirow{3}{*}{$\begin{array}{l}\text { Text } \\
\text { analysis }\end{array}$} & 2.5 & 1.01 & 48.3 & $<$ & 2.4 & 2.6 \\
\hline & 59 & 0 & 44 & .0 & 79 & 40 & & 74 & 6 & 20 & .0 & 7 & 8 \\
\hline & & & & 01 & & & & & & & 01 & & \\
\hline & & & & & & & \multirow{2}{*}{$\begin{array}{l}\text { Rehearsal } \\
\text { and } \\
\text { mnemonics }\end{array}$} & 2.9 & 1.0 & 52.3 & $<$ & 2.8 & 3.0 \\
\hline & & & & & & & & 45 & 74 & 05 & $\begin{array}{l}.0 \\
01\end{array}$ & 3 & 6 \\
\hline \multirow{6}{*}{$\begin{array}{l}\text { Metacogn } \\
\text { itive } \\
\text { strategies }\end{array}$} & 2.7 & .72 & 73.1 & $<$ & 2.7 & 2.8 & \multirow{3}{*}{$\begin{array}{l}\text { Planning } \\
\text { and } \\
\text { Organizing }\end{array}$} & 3.0 & .89 & 64.1 & $<$ & 2.9 & 3.1 \\
\hline & 99 & 9 & 80 & .0 & 24 & 74 & & 16 & 7 & 78 & .0 & 2 & 1 \\
\hline & & & & 01 & & & & & & & 01 & & \\
\hline & & & & & & & \multirow{3}{*}{$\begin{array}{l}\text { Writing } \\
\text { monitoring }\end{array}$} & 2.5 & 1.0 & 45.3 & $<$ & 2.4 & 2.6 \\
\hline & & & & & & & & 82 & 87 & 46 & .0 & 7 & 9 \\
\hline & & & & & & & & & & & 01 & & \\
\hline Environm & 2.5 & .84 & 57.3 & $<$ & 2.4 & 2.61 & Peer & 2.6 & 1.0 & 47.1 & $<$ & 2.5 & 2.7 \\
\hline
\end{tabular}




\begin{tabular}{|c|c|c|c|c|c|c|c|c|c|c|c|c|c|}
\hline \multirow[t]{2}{*}{$\begin{array}{l}\text { ental } \\
\text { strategies }\end{array}$} & \multirow[t]{2}{*}{30} & \multirow[t]{2}{*}{1} & \multirow[t]{2}{*}{53} & \multirow[t]{2}{*}{$\begin{array}{l}.0 \\
01\end{array}$} & \multirow[t]{2}{*}{43} & \multirow[t]{2}{*}{7} & discussion & 35 & 66 & 58 & $\begin{array}{l}.0 \\
01\end{array}$ & 2 & 4 \\
\hline & & & & & & & $\begin{array}{l}\text { Help- } \\
\text { seeking }\end{array}$ & $\begin{array}{l}2.4 \\
26\end{array}$ & $\begin{array}{l}1.0 \\
97\end{array}$ & $\begin{array}{l}42.1 \\
82\end{array}$ & $\begin{array}{l}< \\
.0 \\
01\end{array}$ & $\begin{array}{l}2.3 \\
1\end{array}$ & $\begin{array}{l}2.5 \\
4\end{array}$ \\
\hline \multirow[t]{2}{*}{$\begin{array}{l}\text { Motivatio } \\
\text { nal } \\
\text { strategies }\end{array}$} & $\begin{array}{l}2.91 \\
6\end{array}$ & $\begin{array}{l}.8 \\
08\end{array}$ & $\begin{array}{l}68.8 \\
29\end{array}$ & $\begin{array}{l}< \\
.0 \\
01\end{array}$ & $\begin{array}{l}2.8 \\
32\end{array}$ & $\begin{array}{l}2.9 \\
99\end{array}$ & $\begin{array}{l}\text { Interest } \\
\text { enhance } \\
\text { ment }\end{array}$ & $\begin{array}{l}3.0 \\
33\end{array}$ & $\begin{array}{l}1.0 \\
70\end{array}$ & $\begin{array}{l}54.0 \\
79\end{array}$ & $\begin{array}{l}< \\
.0 \\
01\end{array}$ & $\begin{array}{l}2.9 \\
2\end{array}$ & $\begin{array}{l}3.1 \\
4\end{array}$ \\
\hline & & & & & & & $\begin{array}{l}\text { Performa } \\
\text { nce and } \\
\text { mastery } \\
\text { self-talk }\end{array}$ & $\begin{array}{l}2.7 \\
99\end{array}$ & $\begin{array}{l}1.0 \\
94\end{array}$ & $\begin{array}{l}48.8 \\
26\end{array}$ & $\begin{array}{l}< \\
.0 \\
01\end{array}$ & $\begin{array}{l}2.6 \\
9\end{array}$ & $\begin{array}{l}2.9 \\
1\end{array}$ \\
\hline
\end{tabular}

Note. This is a 5-point Likert scale; $\overline{1}=$ not at all true of me; $2=$ not true of me; $3=$ neutral; $4=$ true of me; $5=$ very true of me; $\mathrm{Cl}=$ confidence interval; $\mathrm{LL}=$ lower limit; $\mathrm{UL}=$ upper limit.

Results demonstrated that all the four dimensions and the eight sub-strategies were significantly different from each other at $p<.001$. Thai EFL learners reported a high level of deploying motivational strategies and a medium level of using metacognitive strategies and cognitive strategies. However, they reported deploying environmental strategies at the lowest level. For the eight sub-strategies, these students reported using planning and organizing and interest enhancement more frequently, followed by rehearsal and mnemonics, performance and mastery self-talk, peer discussion, writing monitoring and text analysis. They reported help-seeking as the least frequently used strategy.

Results showed that grade levels had significant effects on the reported deployment of seven self-regulatory strategies. There was a medium effect on text analysis strategy (Partial $\mathrm{n} 2=$ .074 ), rehearsal and mnemonics (Partial $\mathrm{n} 2=.061$ ), writing monitoring (Partial $\mathrm{n} 2=.092$ ), helpseeking (Partial $\left.\mathrm{n}_{2}=.078\right)$, interest enhancement (Partial $\left.\mathrm{n}_{2}=.064\right)$, a small effect on performance and mastery self-talk (Partial $\mathrm{n}_{2}=.047$ ) and a large effect on peer discussion (Partial $\mathrm{n} 2=.150)($ Cohen, 1988). See Table 3 for the results of MANOVA.

Table 3. Multivariate Analysis of Variance for the Effects of Grade Levels on the Eight Self-regulatory Strategies $(\mathrm{N}=364)$

\begin{tabular}{llll}
\hline Variables & $\mathrm{F}(2,364)$ & $\mathrm{p}$ & $\mathrm{Partial} \mathrm{n} 2$ \\
\hline Text analysis & 14.407 & $<.001$ & .074 \\
\hline Rehearsal and mnemonics & 11.826 & $<.001$ & .061 \\
\hline Planning and Organizing & 1.552 & .213 & .009 \\
\hline Writing monitoring & 18.207 & $<.001$ & .092 \\
\hline Peer discussion & 31.905 & $<.001$ & .150 \\
\hline Help-seeking & 15.310 & $<.001$ & .078 \\
\hline Interest enhancement & 12.281 & $<.001$ & .064 \\
\hline Performance and mastery self-talk & 8.807 & $<.001$ & .047 \\
\hline
\end{tabular}

Table 4. Post Hoc Results of ANOVA of the Seven Selected Self-regulatory Strategies by Grade Levels $(N=364)$

\begin{tabular}{|c|c|c|c|c|c|c|}
\hline \multirow[t]{2}{*}{ Variables } & \multirow{2}{*}{\multicolumn{2}{|c|}{ Grade Level (M) }} & \multirow[t]{2}{*}{ SE } & \multirow[t]{2}{*}{$\mathrm{p}$} & \multicolumn{2}{|c|}{$95 \% \mathrm{Cl}$} \\
\hline & & & & & $\mathrm{LL}$ & UL \\
\hline Text analysis & $\begin{array}{l}\text { Grade } 10 \\
(2.30)\end{array}$ & $\begin{array}{l}\text { Grade } 12 \\
(2.95)\end{array}$ & .126 & $<.001$ & -.95 & -.36 \\
\hline Rehearsal and mnemonics & $\begin{array}{l}\text { Grade } 10 \\
(3.26)\end{array}$ & $\begin{array}{l}\text { Grade } 12 \\
(2.61)\end{array}$ & .134 & $<.001$ & .34 & .97 \\
\hline Writing monitoring & Grade 10 & Grade 12 & .133 & $<.001$ & -1.10 & -.47 \\
\hline
\end{tabular}




\begin{tabular}{|c|c|c|c|c|c|c|}
\hline & $(2.24)$ & $(3.02)$ & & & & \\
\hline & $\begin{array}{l}\text { Grade } 11 \\
(2.49)\end{array}$ & $\begin{array}{l}\text { Grade } 12 \\
(3.02)\end{array}$ & .134 & $<.001$ & -.85 & -.22 \\
\hline \multirow[t]{2}{*}{ Peer discussion } & $\begin{array}{l}\text { Grade } 10 \\
(2.25)\end{array}$ & $\begin{array}{l}\text { Grade } 12 \\
(3.21)\end{array}$ & .126 & $<.001$ & -1.26 & -.66 \\
\hline & $\begin{array}{l}\text { Grade } 11 \\
(2.45)\end{array}$ & $\begin{array}{l}\text { Grade } 1 \\
(3.21)\end{array}$ & .127 & $<.001$ & -1.05 & -.45 \\
\hline \multirow[t]{2}{*}{ Help-seeking } & $\begin{array}{l}\text { Grade } 10 \\
(2.14)\end{array}$ & $\begin{array}{l}\text { Grade } 12 \\
(2.85)\end{array}$ & .136 & $<.001$ & -1.03 & -.39 \\
\hline & $\begin{array}{l}\text { Grade } 11 \\
(2.29) \\
\end{array}$ & $\begin{array}{l}\text { Grade } 12 \\
(2.85) \\
\end{array}$ & .136 & $<.001$ & -.88 & -.24 \\
\hline \multirow[t]{2}{*}{ Interest enhancement } & $\begin{array}{l}\text { Grade } 10 \\
(3.41)\end{array}$ & $\begin{array}{l}\text { Grade } 11 \\
(2.80)\end{array}$ & .133 & $<.001$ & .29 & .92 \\
\hline & $\begin{array}{l}\text { Grade } 10 \\
(3.41)\end{array}$ & $\begin{array}{l}\text { Grade } 12 \\
(2.88) \\
\end{array}$ & .133 & $<.001$ & .21 & .84 \\
\hline $\begin{array}{l}\text { Performance and mastery } \\
\text { self-talk }\end{array}$ & $\begin{array}{l}\text { Grade } 10 \\
(3.06)\end{array}$ & $\begin{array}{l}\text { Grade } 12 \\
(2.49)\end{array}$ & .137 & $<.001$ & .25 & .89 \\
\hline
\end{tabular}

Note. This table only presents the results of selected self-regulated strategies with significant difference at $p$ $<$.001. $\mathrm{Cl}$ = confidence interval; $\mathrm{LL}=$ lower limit; $\mathrm{UL}=$ upper limit.

Table 4 presents post hoc results of the seven self-regulatory strategies. Results revealed that grade 10 students reported a higher level of deploying motivational strategies (interest enhancement and motivational self-talk) and cognitive strategy (rehearsal and mnemonics) than the students in grade 11 and 12. Grade 11 students reported using a higher level of writing monitoring, peer discussion, help-seeking than grade 10 students, but a lower level of interest enhancement than other grade levels. Grade 12 students reported using a higher level of four self-regulatory strategies which were text analysis, writing monitoring, peer discussion, helpseeking than students from other grade levels.

\subsection{Findings in relation to the second research objective}

Findings from the bivariate Pearson correlations with two-tailed significance showed that selfregulatory strategies were significantly correlated with most of self-efficacy (see Table 5).

Table 5. Correlations of Self-regulatory Strategies with Self-efficacy $(N=364)$

\begin{tabular}{|c|c|c|c|c|c|c|c|c|c|}
\hline & & \multicolumn{2}{|c|}{$\begin{array}{l}\text { Cognitive } \\
\text { strategies }\end{array}$} & \multicolumn{2}{|c|}{$\begin{array}{l}\text { Metacognitive } \\
\text { strategies }\end{array}$} & \multicolumn{2}{|c|}{$\begin{array}{l}\text { Environmental } \\
\text { strategies }\end{array}$} & \multicolumn{2}{|c|}{$\begin{array}{l}\text { Motivational } \\
\text { strategies }\end{array}$} \\
\hline & & $\begin{array}{l}\text { Text } \\
\text { Analy } \\
\text { sis }\end{array}$ & $\begin{array}{l}\text { Mnemo } \\
\text { nics \& } \\
\text { Rehears } \\
\text { al }\end{array}$ & $\begin{array}{l}\text { Plannin } \\
\text { g \& } \\
\text { Organiz } \\
\text { ing }\end{array}$ & $\begin{array}{l}\text { Writing } \\
\text { Monitor } \\
\text { ing }\end{array}$ & $\begin{array}{l}\text { Peer } \\
\text { Discussi } \\
\text { on }\end{array}$ & $\begin{array}{l}\text { Help- } \\
\text { seeki } \\
\text { ng }\end{array}$ & $\begin{array}{l}\text { Interest } \\
\text { Enhancem } \\
\text { ent }\end{array}$ & $\begin{array}{l}\text { Self- } \\
\text { talk }\end{array}$ \\
\hline & $\begin{array}{l}\text { Language } \\
\text { Self- } \\
\text { efficacy }\end{array}$ & $.267^{*}$ & $.239^{* *}$ & $.315^{* *}$ & $.139 * *$ & .096 & $.155^{*}$ & $.198 * *$ & $\begin{array}{l}.179 \\
* *\end{array}$ \\
\hline $\begin{array}{l}\text { Self- } \\
\text { Effica }\end{array}$ & $\begin{array}{l}\text { Self- } \\
\text { regulator } \\
\text { y efficacy }\end{array}$ & $.194^{*}$ & $.177^{* *}$ & $.234^{* *}$ & $.259^{* *}$ & $.253^{* *}$ & $.151^{* *}$ & $.212 * *$ & .074 \\
\hline cy & $\begin{array}{l}\text { Writing } \\
\text { performa } \\
\text { nce self- } \\
\text { efficacy }\end{array}$ & $.239 *$ & $.183^{* *}$ & $.306^{* *}$ & $.107^{*}$ & .064 & $.195 *$ & $.344^{* *}$ & $\frac{.323}{* *}$ \\
\hline
\end{tabular}


Table 5 shows that the three aspects of self-efficacy beliefs had significant, positive correlations with all the eight self-regulatory strategies, except for peer discussion and motivation self-talk. Among these, the highest correlation was between interest enhancement and writing performance self-efficacy $(r=.344)$ with a strong effect size, and the lowest was between writing monitoring and writing performance self-efficacy $(r=.107)$ with a minimal effect size. Specifically, cognitive strategies, metacognitive strategies and motivational strategies had small to moderate correlations with all the three aspects of selfefficacy beliefs.

For environmental strategies, help-seeking strategy was significantly related to the three factors of self-efficacy beliefs with small effect sizes, while peer discussion only had a significant, moderate correlation with self-regulatory efficacy.

\subsection{Findings in relation to the third research objective}

\section{Self-regulatory strategies on writing test scores}

Findings revealed that the eight self-regulatory strategies, as a whole, described approximately $47.1 \%$ of the variance in students' writing test scores, $\mathrm{F}(8,363)=39.502, \mathrm{p}<$ $.001, R 2=.471$, adjusted $R 2=.459$. The effect size (Cohen's $f_{2}=.417$ ) indicates that the eight self-regulatory strategies as a whole was a strong factor predicting students' writing test performance (strong effect size $=$ Cohen's $f 2>$. 35, J. Cohen, 1992).

Individual predictors of text analysis, planning and organizing, writing monitoring, peer discussion, help-seeking, interest enhancement and performance and mastery self-talk contributed to significant, positive predictions for students' writing performance. Rehearsal and mnemonics was not significantly related to EFL writing performance. See Table 6 below.

Table 6. Multiple Regression Results of the Eight Self-regulatory Strategies on Writing Test Scores $(N=364)$

\begin{tabular}{llllll}
\hline Sub-categories of self- & $b$ & Beta & $p$ & \multicolumn{2}{l}{$95 \% \mathrm{Cl}$} \\
\cline { 4 - 7 } & & & & $\mathrm{LL}$ & $\mathrm{UL}$ \\
\hline Text analysis & .931 & .107 & .018 & .164 & 1.698 \\
\hline Rehearsal and mnemonics & .135 & .015 & .707 & -.571 & .841 \\
\hline Planning and Organizing & -.955 & -.099 & .024 & -1.783 & -.128 \\
\hline Writing monitoring & .922 & .104 & .010 & .225 & 1.620 \\
\hline Peer discussion & 1.036 & .128 & .003 & .355 & 1.718 \\
\hline Help-seeking & 3.944 & .498 & $<.001$ & 3.276 & 4.612 \\
\hline Interest enhancement & 1.017 & .109 & .018 & .173 & 1.860 \\
\hline Performance and mastery self-talk & 1.242 & .145 & .003 & .431 & 2.052 \\
\hline
\end{tabular}

Note. The dependent variable was writing test score. $\mathrm{R2}=.471$, Adjusted $\mathrm{R} 2=.459 ; \mathrm{Cl}=$ confidence interval; $\mathrm{LL}$ = lower limit; UL = upper limit.

\section{Self-efficacy on writing test scores}

The three variables of self-efficacy beliefs were entered as a group to predict writing test scores in a multiple regression model. Adjusted alpha value was at .019. Multiple regression analysis shows that these self-efficacy beliefs predicted $10.1 \%$ of variance in writing test scores $\mathrm{F}(3,363)=13.555, \mathrm{p}<.001, \mathrm{R} 2=.101$, adjusted $\mathrm{R} 2=.094$, suggesting a medium effect size (Cohen's $f_{2}=.195$ ). For each factor of self-efficacy beliefs, only language self-efficacy and writing performance self-efficacy showed a significant difference to predict writing test scores $(\beta=.204, p<.001$ and $\beta=.180, p<.001)$. See Table 7 below. 
Table 7. Multiple Regression Results of Self-efficacy on Writing Test Scores $(N=364)$

\begin{tabular}{|c|c|c|c|c|c|}
\hline \multirow[t]{2}{*}{ Self-efficacy } & \multirow[t]{2}{*}{8} & \multirow[t]{2}{*}{ Beta } & \multirow[t]{2}{*}{$p$} & \multicolumn{2}{|c|}{$95 \% \mathrm{Cl}$} \\
\hline & & & & LL & UL \\
\hline Language Self-efficacy & 1.597 & .204 & $<.001$ & .802 & 2.392 \\
\hline Self-regulatory efficacy & .725 & .076 & .146 & -.253 & 1.702 \\
\hline Writing Performance Self-efficacy & 1.473 & .180 & $<.001$ & .653 & 2.292 \\
\hline
\end{tabular}

\subsection{Discussion}

\subsubsection{Self-regulatory strategies}

The descriptive analysis reveals that the Thai high school students reported imbalanced deployment of self-regulatory strategies at relatively low levels.

By comparing the four dimensions of self-regulatory strategies, all the respondents reported a medium level of deploying motivational strategies, cognitive strategies and environmental strategies, and a low level of metacognitive strategies. However, the order of preference reported in this study is not consistent with the findings in some earlier studies (Baker \& Boonkit, 2004; Charoensuk \& Jaipetch, 2017; lamla-ong, 2013; Pawapatcharaudom, 2007). lamla-Ong (2013), Pawapatcharaudom (2007), and Baker and Boonkit (2004) studied which language learning strategies were employed by Thai students at the university level. The results showed that students used metacognitive strategies (Baker \& Boonkit 2004; Taher et al., 2016), and compensation strategies more frequently (Baker \& Boonkit 2004; Charoensuk \& Jaipetch 2017; Pawapatcharaudom, 2007). However, McMullen's (2009) study revealed that deploying language learning strategies to develop the writing skills of Saudi EFL learners showed that the learners preferred social, metacognitive, and compensation strategies. Baker and Boonkit (2004) revealed the strategies students deploy the most were using background knowledge to generate an idea for writing, depending on a dictionary, and learning from peers. Lan and Oxford's (2003) study revealed that Taiwanese students of English employed compensation strategies and affective strategies more frequently, followed by metacognitive strategies, cognitive strategies, social strategies and memory strategies.

The Thai EFL students in this study showed a relatively medium level of motivational strategies, particularly strategies for interest enhancement. Similarly, these students reported a high level of cognitive strategies, rehearsal and mnemonics use. This suggests that Thai EFL high school students were likely to deploy some strategies to enhance their interest and regulate their negative feelings in order to concentrate on and maintain their efforts when completing a writing task.

However, these students reported the lowest level of using metacognitive strategies, particularly writing monitoring in EFL contexts. The findings of the study conducted by Zhan (2012) have suggested that the low level of deploying planning strategies might be due to the fact that several students perceive writing as a non-stop process, therefore paying attention to producing a whole piece of written text instead of deploying various methods to produce clear ideas before writing. The important role of metacognitive strategies has been acknowledged in developing writing competence and supporting self-regulated learners in L2 settings (Harris, Santangelo \& Graham, 2010). Thus, it is important to teach EFL students the 
value of the strategies and how to apply them in their learning processes in writing courses in schools.

These Thai EFL students reported using a medium level of cognitive strategies: text analysis and rehearsal and mnemonics. The medium level of deploying text analysis strategies might be attributed to the demanding nature of employing these cognitive strategies. In this study, the text analysis strategies cover students' deployment of language, rhetorical and discourse knowledge in writing, and the revising processes, reflecting the recursive process of writing from a cognitive view (Flower \& Hayes, 1981). However, some students were willing to revise their writing, but they often felt discouraged and unmotivated due to limited language knowledge or lack of strategy instruction in regular writing courses. Rehearsal and mnemonics examine how students try to remember what is taught in writing courses, showing a degree of knowledge memory. The results of this study showed a medium level of using rehearsal and mnemonics strategies in EFL writing.

The study also shows that Thai EFL students actively deployed environment resources to reduce their cognitive and psychological burden in learning to write. The findings indicate that these students showed a high level of using help-seeking and peer discussion strategies. Peer discussion means strategies students use to cooperate with others in groups and deal with feedback on their writing, such as attempting to remember or writing down others' suggestions and checking mistakes after receiving written works back from teachers. For help-seeking strategy, it shows how students seek help from others to help their learning such as working with peers to produce more ideas to write. Another possible explanation for the high level of using environmental strategies is the teacher-centered learning method in writing instruction, which might make students think that teachers' feedback was an important resource to help them to produce desirable written work in writing classrooms.

\subsubsection{Self-regulatory strategies and grade levels}

A series of MANOVAs reveals that grade level had a significant effect on the use of seven selfregulatory strategies (i.e., text analysis, rehearsal and mnemonics, writing monitoring, peer discussion, help-seeking, interest enhancement, performance and mastery self-talk). Grade 9 and 10 were more likely to use a higher level of cognitive strategies (i.e., rehearsal and mnemonics) and motivational strategies (i.e., interest enhancement and performance and mastery self-talk) than Grade 12 did. For example, Grade 10 and 11 students tended to deploy some strategies to help their understanding and deploy the knowledge they have learned in writing courses, and enthusiastically select the appropriate emotional stimuli that will arouse positive emotions to writing by relating them to their personal interests. In addition, the students might deploy self-talk statements, such as aiming for a good grade in writing tests as a goal for maintaining their learning efforts.

Grade 12 students reported using the highest level of text analysis, writing monitoring, peer discussion and help-seeking than students of lower grade levels. These students tended to set up goals to drive or guide their learning; to utilize peer discussion strategy to help them write; and to link what they learned with their own interest to maintain their learning efforts. These changes indicate that the students had more cognitive regulation so that they might not have strong negative feelings in the learning process when compared to the grade 10 and 11 students. On the other hand, they were more enthusiastic in deploying environmental strategy, such as seeking help from peers to help their learning. 
The significant differences between the grade levels and the deployment of self-regulatory strategies also help explain how to teach writing strategies by considering the differences in grade levels to enhance better learning outcomes.

\subsubsection{Self-regulatory strategies and self-efficacy}

This study revealed that students' self-efficacy were related to their utilization of various selfregulatory strategies. The significant correlations provide support to a sociocognitive view of self-regulation, which focuses on the influence of behaviours, people, and environments in the learning process (Zimmerman, 2013).

The three aspects of self-efficacy were significantly correlated with self-regulatory strategies. Therefore, learners' positive confidence in their language, self-regulatory strategies, and writing competence might influence motivational support for their cognitive engagement, metacognitive control, and motivational regulation when they complete a writing task (Graham, 2007).

Moreover, self-regulatory efficacy was strongly correlated with all the eight self-regulatory strategies with larger effect sizes when compared to the other two dimensions. According to Zimmerman and Bandura (1994), "learners' belief in their self-regulatory efficacy identifies how well subskills are integratedly employed and sustained" (p. 38).

Thus, the different correlations between the three aspects of self-efficacy and self-regulatory strategies provide support to an argument that the self-efficacy belief system is "a differentiated set of self-beliefs linked to distinct realms of functioning" (Bandura, 1986: 36).

\subsubsection{Self-regulatory strategies and writing performance}

The findings showed that the eight self-regulatory strategies were significant predictors of writing test scores. This shows that students who use a higher level of self-regulatory strategies would have better academic writing performance.

For the cognitive strategies, both text analysis and rehearsal and mnemonics strategies produced a significant prediction for writing test scores. This shows that students' employment of language and writing knowledge is an important factor impacting their writing performance as shown in other research (e.g., Bai, 2015). The result also supports other findings, which have argued for the important role of cognitive processes in nurturing active engagement in the learning process and promoting students' writing outcomes (e.g., Flower \& Hayes, 1980). In addition, knowledge rehearsal was a significant predictor of writing test scores. This means that the remembrance of learning material or course knowledge, as a kind of surface strategy has a direct impact on individuals' writing test scores. According to Hofer, $\mathrm{Yu}$ and Pintrich (1998), it is assumed that these rehearsal strategies will help learners pay attention to and identify important information from lists or texts and hold this information active in the working memory.

Regarding the metacognitive strategies, planning and organizing and writing monitoring made a significant contribution in the learners' composing test scores, implying that the EFL students who employed deeper processing strategies tended to have higher scores in composing tests. This shows that students who employ some strategies to produce more ideas seem to have higher scores in composing tests. This is in line with the previous research 
on LLSs in general contexts. The findings provide empirical evidence to the significant effect of planning and organizing strategies on L2 writing performance (Raimes, 1985).

Writing monitoring strategies (e.g., setting up goals to direct learning activities; monitoring learning goal in writing courses) were also a significant factor to students' academic performance, therefore contributing to empirical evidence supporting the cognitive view of the writing process as a goal-directed activity (Flower \& Hayes, 1980). Results from this phase further support the claim that, in the self-regulating process, writers personally "activate and sustain cognitions, affects and behaviours that are systematically oriented toward the attainment of personal goals" (Zimmerman \& Schunk, 2011, p. 1).

According to Harris, Santangelo and Graham (2010), metacognitive strategies foster the development of language proficiency and cognitive maturity in improving self-regulated learners. Therefore, it is essential to integrate metacognitive strategies, especially writing monitoring, into EFL writing classrooms to enhance the learners' writing performance and to nurture more efficient and active writers.

Regarding the environmental strategies, peer discussion and help-seeking were significant predictors of writing performance. Similarly, feedback handling contributes to the significant effect on learners' composing test scores. In addition, Schunk and Zimmerman (2007) agreed that, within the cyclical model of self-regulatory learning, feedback facilitates the individuals' monitoring and self-evaluation in the self-regulatory process, leading to positive learning outcomes. Therefore, this study provides tentative support for the impact of environmental strategies on an individual's writing performance in EFL contexts.

In terms of the motivational strategies, both interest enhancement and performance and mastery self-talk significantly influenced the students' writing performance.

For performance and mastery self-talk in this study, the significant result shows that students who employed intrinsic and extrinsic reasons (performance and mastery self-talk) to motivate them to learn and/or maintain their learning efforts seemed to have higher scores in composing tests. This result reflects another study in other settings (Schwinger et al., 2009). For instance, Schwinger et al. (2009) revealed that mastery self-talk had an indirect impact on test performance in German contexts.

To summarize, the findings of multivariate analyses reveal the essential role of self-regulatory strategies in enhancing writers' academic performance in EFL settings. The results provide support to some previous studies on LLSs, in terms of positive relationship between writing strategies and language learning outcomes in general or in specific writing contexts (Bai, Hu \& $\mathrm{Gu}, 2014$; Baker \& Boonkit, 2004). These results together provide evidence to support earlier studies that individuals' learning achievement is directly affected by their self-regulation of "cognition, motivation, and behavior that mediate the relations between the person, context, and eventual achievement" (Pintrich, 2004, p. 388).

\subsubsection{Self-efficacy on writing performance}

The three sub-sets of self-efficacy as a whole showed a significant predictive effect on students' writing test performance, which is in line with the results of previous studies (e.g., Bandura, 1997; Zimmerman \& Bandura, 1994). 
This study showed that self-regulatory efficacy was a significant predictor of students' writing test scores among the three aspects of self-efficacy. This result reflects Zimmerman and Bandura (1994)'s study who found that self-regulatory efficacy had both direct and indirect impacts on writing course grades. It might be inferred that no consistent agreement has been concluded regarding the relationship between self-efficacy beliefs and academic performance. These differences might be due to the way in which self-efficacy is investigated as a holistic construct or a multidimensional construct. According to Bruning et al (2013), the direct and indirect effects of self-efficacy on writing test performance shows that people's belief in their efficacy is a dynamic and complex construct consisting of different factors.

\section{Conclusion}

The findings show that Thai EFL high school students reported using different self-regulatory strategies in terms of cognition, metacognition, environment and motivation at different levels. These results show the importance of investigating self-regulatory strategies from four dimensions to describe a holistic picture of self-regulation processes (Zimmerman, 2013). Moreover, students' grade level was a significant factor affecting their deployment of these strategies.

The different correlations between self-regulatory strategies and self-efficacy show that the use of learning strategies is a complex process under the influence of multiple variables (Zimmerman, 2013). Moreover, results show mixed support for the predictive effects of selfregulatory strategies and self-efficacy on writing performance. Writing achievement depends on the deployment of self-regulatory strategies, which play an important role in sustaining learning efforts and impacting students' academic performance. The data from this phase implies that students' self-efficacy in their capability is a motivational base for students' effective engagement in academic learning (Pajares, 2008), showing that the development of strategic writers needs an integration of both self-regulatory strategies and motivational factors.

Data from this study show that students needed to be taught skills and strategies in executing both the cognitive aspects of managing learning, and methods to motivate themselves for academic pursuits when they face obstacles or attractive options (Zimmerman \& Bandura, 1994).

\section{Acknowledgement}

This article was a part of the research entitled "Facilitating Learners' Self-Regulated Learning Skills and Self-efficacy to Write in English and Writing Performance through Constructivist Selfregulating Virtual Composing Activities" supported by a grant from Thaksin University in 2017.

\section{References}

Bai, R. (2015). The effects of strategy-based writing instruction in Singapore primary schools. System, 53, 96-106.

Bai, R., Hu, G., \& Gu, Y. (2014). The relationship between writing strategies and English proficiency in Singapore primary schools. Asia-Pacific Education Researcher, 23, 355365. 
Baker, W., \& Boonkit, K. (2004). Learning strategies in reading and writing: EAP contexts. RELC Journal, 35(3), 299-328.

Bandura, A. (1986). Social foundations of thought and action: A social cognitive theory. Upper Saddle River, NJ 07458: Prentice-Hall, Inc. A Pearson Education Company.

Bandura, A. (2006). Guide for constructing self-efficacy scales. In F. Pajares \& T. Urdan (Eds.). Self-efficacy beliefs of adolescents (Vol. 5., pp. 307-337). Greenwich, CT: Information Age Publishing.

Bandura, A. (1997). Self-efficacy: The exercise of control. New York: W. H. Freeman.

Bouffard-Bouchard, T., Parent, S., \& Larivee, S. (1991). Influence of self-efficacy on selfregulation and performance among junior and senior high-school age students. International Journal of Behavioral Development, 14(2), 153-164.

Bruning, R., Dempsey, M., Kauffman, D. F., McKim, C., \& Zumbrunn, S. (2013). Examining dimensions of self-efficacy for writing. Journal of Educational Psychology, 105(1), 25-38.

Charoensuk, V., \& Jaipetch, D. (2017). Attitudes toward English, a study of first-year students at King Mongkut's university of technology North Bangkok. Journal of Advances in Humanities and Social Sciences, 3(1), 42-57.

Cohen, J. (1988). Statistical power analysis for the behavioral sciences (2nd ed.). Hillsdale, NJ Lawrence Erlbaum Associates, Publishers.

de Bruin, A. B., Thiede, K. W., \& Camp, G. (2011). Generating keywords improves metacomprehension and self-regulation in elementary and middle school children. Journal of Experimental Child Psychology, 109(3), 294-310.

Flower, L., \& Hayes, J. R. (1981). A cognitive process theory of writing. College Composition and Communication, 32(4), 365-387.

Flower, L., \& Hayes, J. R. (1980). The dynamics of composing: Making plans and juggling constraints. In L. Gregg \& E. Steinberg (Eds.), Cognitive processes in writing (pp. 31-50). Hillsdale, NJ: L. Erlbaum.

Graham, S. (2007). Learner strategies and self-efficacy: Making the connection. Language Learning Journal, 35(1), 81-93.

Graham, S., Harris, K. R., \& Mason, L. (2005). Improving the writing performance, knowledge, and motivation of struggling young writers: The effects of self-regulated strategy development. Contemporary Educational Psychology, 30, 207-241.

Hall, D. (1988). Writing well. Boston: Little, Brown and Company.

Harris, K. R., Friedlander, B. D., Saddler, B., Frizzelle, R., \& Graham, S. (2005). Self-monitoring of attention versus self-monitoring of academic performance: Effects among students with ADHD in the general education classroom. Journal of Special Education, 39(3), 145156.

Harris, K. R., Graham, S., MacArthur, C., Reid, R., \& Mason, L. H. (2011). Self-regulated learning processes and children's writing. In B. J. Zimmerman, \& D. H. Schunk (Eds.), Handbook of self-regulation of learning and performance (pp. 187-202). New York, NY: Routledge.

Harris, K. R., Santangelo, T., \& Graham, S. (2010). Metacognition and strategies instruction in writing. In H. S. Waters, \& W. Schneider (Eds.), Metacognition, strategy use, and instruction (pp. 226-256). New York, NY: Guilford.

Hofer, B. K., Yu, S. L., \& Pintrich, P. R. (1998). Teaching college students to be self-regulated learners. In D. H. Schunk, \& B. J. Zimmerman (Eds.), Self-Regulated learning: From teaching to self-reflective practice (pp. 57-85). New York, NY: The Guilford Press.

lamla-ong. (2013). Language learning problems \& language learning strategies of MFU students. MFU Connexion, 2(1), 58-91.

Jacobs, H. L., Zingraf, S. A. Wormuth, D. R., Hartfiel, V. F., \& Hughey, J. B. (1981). Testing ESL composition: a practical approach. Rowley, Massachusetts: Newbury House. 
Jarvela, S., \& Jarvenoja, H. (2011). Socially constructed self-regulated learning in collaborative learning groups. Teachers College Records, 113(2), 350-374.

Kellogg, R. (2001). Long-term working memory in text production. Memory and Cognition, 29(1), 43-52.

Lan, R., \& Oxford, R. L. (2003). Language learning strategy profiles of elementary school students in Taiwan. International Review of Applied Linguistics in Language Teaching, 41(4), 339-380.

Lee, L. H. (1997). Goal orientation, goal setting, and academic performance in college students: An integrated model of achievement motivation in school settings. Dissertation Abstracts International, 59(06), 1905A. (UMI 9835095).

Magno, C. (2009). Self-Regulation and approaches to learning in English writing. Philippine ESL Journal, 1, 1-16.

McMullen, M. G. (2009). Using language learning strategies to improve the writing skills of Saudi EFL students: Will it really work? System, 37(3), 418-433.

Pajares, F. (2007). Empirical properties of a scale to assess writing self-efficacy in school contexts. Measurement and Evaluation in Counseling and Development, 39(4), 239-249.

Pajares, F. (2008). Motivational role of self-efficacy beliefs in self-regulated learning. In D. H. Schunk, \& B. J. Zimmerman. (Eds.), Motivation and self-regulated learning: Theory, research, and applications (pp. 111-139). New York, NY: Erlbaum.

Pawapatcharaudom, R. (2007). An investigation of Thai students' English language problems and their learning strategies in the international program at Mahidol University. Unpublished Master's Thesis, King Mongkut's Institute of Technology North Bangkok.

Pintrich, P. R. (2004). A conceptual framework for assessing motivation and self-regulated learning in college students. Educational Psychology Review, 16(4), 385-407.

Pintrich, P. R., Smith, D. A., Garcia, T., \& McKeachie, W. J. (1991). A manual for the use of the Motivated Strategies for Learning Questionnaire (MSLQ). Ann Arbor, MI: University of Michigan.

Raimes, A. (1985). What unskilled ESL students do as they write: A classroom study of composing. TESOL Quarterly, 19(2), 229-258.

Schunk, D. H., \& Zimmerman, B. J. (2007). Influencing children's self-efficacy and selfregulation of reading and writing through modeling. Reading \& Writing Quarterly, 23(1), $7-25$.

Schunk, D., \& Zimmerman, B. (1997). Social origins of self-regulatory competence. Educational Psychologist, 32(4), 195-208.

Schunk, D. H., \& Zimmerman, B. J. (1994). Self-Regulation of learning and Performance: Issues and educational applications. Hillsdale, NJ: Lawrence Erlbaum Associates.

Schwinger, M., Steinmayr, R., \& Spinath, B. (2009). How do motivational regulation strategies affect achievement: Mediated by effort management and moderated by intelligence. Learning and Individual Differences, 19(4), 621-627.

Taher, D., Landry, S., \& Toussaint, J. (2016). Breadth vs. depth: how to start deploying the daily management system for your lean transformation. Journal of Hospital Administration, 5(6), 90-96.

Teng, L. (2016). Fostering strategic second-language writers: A study of Chinese English-as-aForeign-Language (EFL) writers' self-regulated learning strategies, self-efficacy and motivational beliefs. Doctoral dissertation. The University of Auckland, Auckland New Zealand.

Wolters, C. A. (2011). Regulation of motivation: Contextual and social aspects. Teachers College Record, 113(2), 265-283. 
Zhan, J. (Eds.). (2012). English writing in social-cultural contexts: Proceedings of the 7th International Conference on Teaching and Researching EFL Writing in China. Beijing, China: FLTRP.

Zimmerman, B. J. (2013). From cognitive modeling to self-regulation: A social cognitive career path. Educational Psychologist, 48(3), 135-147.

Zimmerman, B. J., \& Bandura, A. (1994). Impact of self-regulatory influences on writing course attainment. American Educational Research Journal, 31(4), 845-862.

Zimmerman, B. J., \& Martinez-Pons, M. (1992). Perceptions of efficacy and strategy use in the self-regulation of learning. In D. H. Schunk, \& J. L. Meece (Eds.), Student perceptions in the classroom: Causes and consequences (pp. 185-207). Hillsdale, NJ: Erlbaum.

Zimmerman, B. J., \& Schunk, D. H. (2011). Self-regulated learning and performance: An introduction and an overview. In B. J. Zimmerman, \& D. H. Schunk (Eds.), Handbook of self-regulation of learning and performance (pp. 1-12). New York, NY: Routledge.

Zimmerman, B. J. (2002). Becoming a self-regulated learner: An overview. Theory into Practice, 41(2), 64-70.

\section{Biographical notes:}

Kretsai Woottipong is a lecturer at Thaksin University. She received her master degree in Applied Linguistics for Teaching from Prince of Songkhla University, Thailand. Her research interests include English language teaching and technology and ESL Writing and Grammar. 